Revista de Derecho YACHAQ N ${ }^{\circ}$ - Diciembre de 2017

Centro de Investigación de los Estudiantes de Derecho (CIED)

Universidad Nacional de San Antonio de Abad del Cusco

ISSN: 2707-1197(en línea)

ISSN:1817-597X(impresa)

Fecha de recepción: 18/09/17

Fecha de aceptación:27/10/17

(pp. 31-60)

\title{
La Constitución y el Derecho a la Igualdad
}

\author{
The Constitution and the Right to Equality
}

Víctor García Toma $\left(^{*}\right)$

RESUMEN: Desde hace muchos años, las personas, los estados y la sociedad en general, han ido trabajando por un derecho, que actualmente consideramos inherente a la persona humana, este es el derecho a la igualdad, por el respeto de este derecho se dieron guerras, enfrentamientos, luchas y sobre todo muertes de hombres quienes creían que la igualdad cambiaria de buena fe el rumbo de las sociedades. Actualmente, es parte fundamental de nuestra Carta Magna, y diversos organismos Internacionales velan por garantizar este derecho a nivel mundial, todos somos iguales ante la ley, es un principio fundamental para el derecho y diferentes doctrinarios sustentaran las ideas conceptuales sobre igualdad, así también nuestra Jurisprudencia Peruana toma este derecho fundamental como base para dictar resoluciones, todo en el marco del respeto a la igualdad.

Palabras Clave: Igualdad, Principio fundamental, Jurisprudencia, derecho

\begin{abstract}
For many years, people, states and society in general, have been working for a right, which we currently consider inherent to the human person, this is the equality right, for the respect of this right there were wars, confrontations, struggles and especially deaths of men who believed that equality would in good faith change the course of societies. Currently, it is a fundamental part of our Magna Carta, and various international organizations ensure that this right is guaranteed worldwide, we are all equal before the law, it is a fundamental principle for the law and different doctrinaires will support the conceptual ideas on equality, as well as our Peruvian Jurisprudence takes this fundamental right as the basis for issuing resolutions, all within the framework of respect for equality.
\end{abstract}

Key Words: Equality, Fundamental Principle, Jurisprudence, law

$\left({ }^{*}\right)$ Abogado graduado en la Universidad San Martín de Porres y Magíster en Derecho Constitucional en la Universidad Nacional Federico Villarreal. Decano de la Facultad de Derecho de la Universidad de Lima y Catedrático del Instituto de Gobierno de la Universidad de San Martin de Porres.garciatoma@hotmail.com 


\section{La Constitución y El Derecho a La IGUALDAD}

\author{
Víctor García Toma \\ Abogado graduado en la \\ Universidad San Martín \\ de Porres y Magíster en \\ Derecho Constitucional en \\ la Universidad Nacional \\ Federico Villarreal. Decano \\ de la Facultad de Derecho \\ de la Universidad de Lima y \\ Catedrático del Instituto de \\ Gobierno de la Universidad \\ de San Martin de Porres.
}

SUMARIO: 1.- La conceptualización de la igualdad, 2.- La igualdad como principio, 3.- La igualdad como derecho, 4.- La distinción entre igualdad como principio e igualdad como derecho, 5.- Los ámbitos de aplicación del principio-derecho de igualdad, 6.- La igualdad y la diferenciación, 7.- La igualdad y la discriminación, 7.1.- La discriminación y el criterio de término de comparación, 8.- La ponderación: El test de la igualdad, 9.- La acción positiva, afirmativa o de discriminación inversa

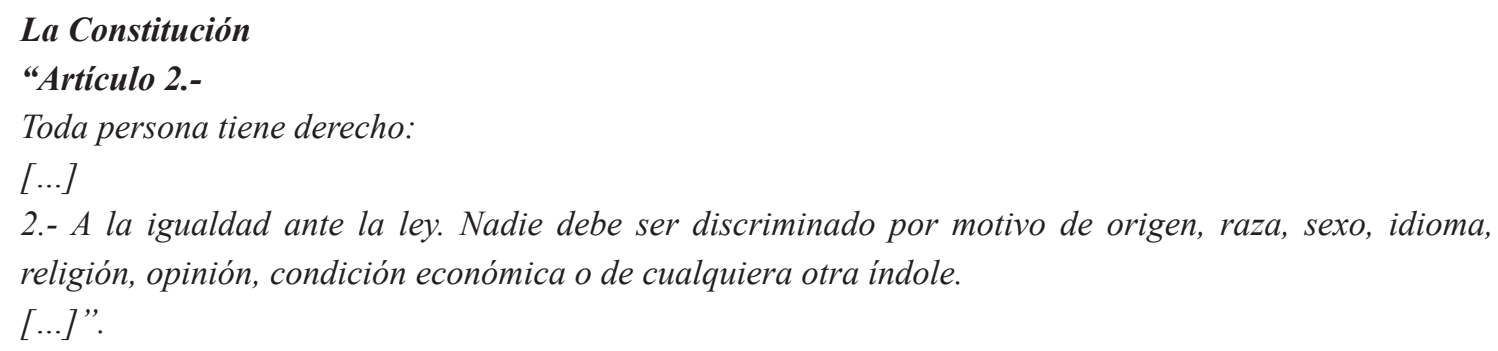

$\mathbf{E}$ ste principio-derecho se encuentra previsto en el inciso 2 del artículo 2 de la Constitución vigente y en el inciso 1 del artículo 26 del mismo texto.

En nuestro país su regulación constitucional se inicia en el texto de 1823.

De manera concordante y con sujeción a lo establecido en la Cuarta Disposición Final y Transitoria de la Constitución, el derecho objeto de comentario se encuentra contemplado en los artículos 1, 2 y 7 de la Declaración Universal de los Derechos Humanos; el artículo II de la Declaración Americana de los Derechos y Deberes del Hombre; los artículos 2 y 26 del Pacto Internacional de los Derechos Civiles y Políticos; los artículos 1, 2, 13 y 24 de la Convención Americana sobre Derechos Humanos; y en la Convención Interamericana contra el racismo, la Discriminación y Formas Conexas de Intolerancia. 
Se trata de un principio democrático de organización de la sociedad política y de un fundamento para el goce de los demás derechos constitucionales.

Desde una perspectiva histórica, el derecho a la igualdad es una de las conquistas más sentidas de las revoluciones burguesas de finales del siglo XVIII (Francia, EE UU). En suma, tuvo una raigambre liberal; cuya característica inicial consistió en concebir a la ley como una expresión normativa vinculante y compelida de generalidad y abstractividad; amén del reconocimiento de una simétrica capacidad jurídica para todas las personas sin ningún tipo de distinción social.

Mariano Azuela Guitran [Derecho, sociedad y libertad. México: Universidad Iberoamericana, 1995], expone que los revolucionarios franceses se rebelaron contra el principio de privilegio establecido en el Medioevo, en donde la ubicación social -registrada desde el nacimiento- distinguía entre los derechos de la nobleza, la clerecía y el pueblo.

Con la imposición de esta idea-fuerza liberal se combatió los privilegios y arbitrariedades de clase y de casta.

Así, en el artículo 1 de la Declaración de los Derechos del Hombre y del Ciudadano (Francia, 1789) se consignó que: "Todos los hombres nacen y viven libres e iguales en derechos; las distinciones sociales solo pueden fundarse en la utilidad común".

Más aún, en el artículo 6 se señaló que: "La ley es la expresión de la voluntad general. Todos los ciudadanos tiene el derecho de concurrir a su formación personalmente o por representantes. Ella debe ser la misma para todos, lo mismo cuando proteja como cuando castigue. Siendo todos los ciudadanos iguales ante ella, son igualmente admisibles a todas las dignidades, cargos y empleos públicos, según su capacidad, sin otra distinción que la de su virtud o la de su talento".

En el Acta de Independencia de los Estados Unidos de fecha 4 de julio de 1776 se proclamó: "Sostenemos como verdades evidentes que todos los hombres han sido creados iguales [...].

Ningún hombre o grupo de hombres tiene derecho, privilegio o ventajas exclusivas o separadas de la comunidad".

Francisco Fernández Segado [El sistema constitucional español. Madrid: Dykinson, 1992], refiere que en el pensamiento liberal de finales del siglo XVIII y a lo largo del siglo XIX, el principio de igualdad se manifestaba básicamente como una paridad ante la ley. Esto es, como una equiparidad sin acepción de las personas, en torno a los alcances normativos de un precepto legal.

La afirmación del principio de igualdad como referente coexistencial moderno fue ideológicamente aparejada con el concepto de libertad. Su presencia destruyó todo vestigio de funcionamiento estamental de la sociedad.

Al respecto, recordemos la interrogante que se formulaba el dramaturgo Pierre Agustín Carón de Beaumarchais, en su obra Las Bodas de Figaro (1779): “QQue habéis hecho para merecer tanto bien? Habéis nacido, nada más”. 
La obligación del naciente Estado Liberal consistía en que el contenido normativo de sus disposiciones, debían sustentarse en la proscripción de toda referencia al status social y jurídico forjado en la idea del derecho preeminente por razón del nacimiento o por el otorgamiento regio de un privilegio.

Daniel Mendonca [Apuntes constitucionales. Una guía para el ciudadano. Asunción: Intercontinental Editora, Centro de Estudios Constitucionales, 2012] señala que la igualdad formal era configurada "como una equiparación de posiciones de los destinatarios de la ley ante sus efectos y alcances. Este carácter puramente formal cobraba peculiar relevancia [...] desde la existencia de una sociedad fragmentada en sus estamentos regidos por ordenes diferentes".

En puridad, esta concepción rupturista con el “Antiguo Régimen” que dividía jurídicamente a los hombres tercialmente en nobleza, clerecía y pueblo, más allá de apuntar a la eliminación de los privilegios de casta, aspiraba a la consagración principista del concepto de la generalidad y abstractividad de la norma dictada por la autoridad política; así como a la eficacia erga onmes de las disposiciones legales, a las que debían sujetarse todos los individuos sin distinción.

En ese contexto, el principio de igualdad quedó subsumido dentro del principio de legalidad. Por consiguiente, se consignaba como iguales a aquellos a quienes la ley consideraba como tales, y diferentes a aquellos otros a quienes ella misma diferenciara.

En ese sentido, la ley era igual para todos, porque esta reunía las características de universalidad y generalidad.

En razón de la primera, la determinación normativa exponía el conjunto de ideas esenciales referidas a una específica forma de relación jurídica; lo que le daba a dicho tipo de ligazón una naturaleza o carácter común.

En razón de la segunda, la determinación normativa se extendía indistintamente a todos los vínculos jurídicos del mismo género y especie.

Es evidente que dentro de dicho marco histórico-ideológico, la vigencia y aplicabilidad del principio de igualdad quedaba supeditada a la voluntad del legislador. Este tenía como principal punto de orientación para consagrar dicha equiparidad personal, la imposibilidad de establecer diferencias que no resultaren del libre juego de las fuerzas sociales. En ese sentido, se postuló la neutralidad e imparcialismo del cuerpo político frente a sus súbditos o ciudadanos.

Francisco Rubio Llorente ["El principio de legalidad”. En: Revista Española de Derecho Constitucional, Año 13, $N^{\circ}$ 30. Madrid: CEC, 1993] establece que la sociedad civil como hecho oriundo y ajeno al Estado, no encontraba obstáculo para considerar naturales y consecuentemente juridizables las diferencias que ella misma estableciere.

Tal como puede desprenderse de sus prístinos enunciados ideológicos, la clásica enunciación de la igualdad ante la ley constituye una igualdad formal; la cual devenía en insuficiente a la luz de las reflexiones que nos brinda la historia de la coexistencia social. 
El cambio de orientación del sentido de la igualdad, se generará con la aparición de las corrientes políticas revolucionarias post-liberales (socialdemócrata, anarquista, marxista, etc.) y por la propia doctrina social de la Iglesia. A raíz de ello, se comenzará a reivindicar la necesidad de que la igualdad no sea concebida exclusivamente en términos formales, sino que adquiera complementariamente un sentido material. Esto es, que, la igualdad en el goce pleno de los derechos fundamentales y la búsqueda de la plena realización personal se convierte en un logro o meta histórica a alcanzar mediante la actuación directa o indirecta del denominado Estado Social.

A partir de allí se comienza a reivindicar la necesidad que la igualdad no sea concebida como un principio exclusivamente formal, sino que la equiparidad de oportunidades se convierta en un objetivo o meta a alcanzar mediante la actuación del Estado.

Por ende, para que todos los seres humanos podamos tener acceso a las mismas oportunidades de realización personal y coexistencial; y para que los beneficios de la ley no devengan en una quimera, es preciso que se atenúen los desequilibrios estructurales que infraccionan el orden natural.

A la denominada igualdad ante ley, hay que confrontarla en la praxis con la denominada igualdad sustancial; lo que se traduce en la verificación efectiva de todo aquello que la primera enuncia. Se trata de comprobar de qué modo ello se cumple, en función de una serie de condicionamientos de carácter económico, social, cultural, etc.

Para tal efecto, el "encuentro de vida" (político-social) no debe ser un cepo o factor obstruyente - por ende discriminador - para el pleno desenvolvimiento de las capacidades naturales; así como las fundadas aspiraciones de realización personal.

Es obvio que la desigualdad real evidentemente influirá en la materialización de los alcances y contenidos de la ley. Domingo García Belaúnde [Teoría y práctica de la Constitución peruana. Lima: Eddili, 1989], plantea como ejemplo, que el condicionamiento económico para el cabal ejercicio del derecho de defensa, permitirá o impedirá según sea el caso, el contar con la asistencia de un abogado competente.

El cambio de contenidos en el principio de igualdad alcanzará mayoría de edad mediante la orientación jurisprudencial emprendida por el Tribunal Constitucional alemán; el mismo que fue dirigido en buena parte por el jurista Gelehard Leibholz, durante el período de entre guerras (1919-1939). A ello hay que agregar el aporte del Tribunal Constitucional italiano a partir de 1947.

\section{1.- La conceptualización de la igualdad}

La igualdad es un derecho relacional, en donde el nexo de su aplicación reposa sobre un mismo derecho, carga pública, bien tutelado o interés protegido.

Este tiene que ver con la misma identidad jurídica (requisitos, circunstancias, condiciones, etc.) en relación al mismo atributo o responsabilidad establecida en una norma. 
La igualdad como concepto relacional solo se revela en función a la respuesta de las consideraciones siguientes:

a) Patrón de parangón (fuente jurídica que sirve de parámetro de comparación).

b) Igualdad entre quienes (personas naturales o jurídicas).

c) Igualdad respecto a qué (condición, circunstancias, requisitos, etc.).

d) Igualdad para qué (reconocimiento o ejercicio o determinación de un derecho, deber, sanción, etc.).

Dichas consideraciones tienen sentido cuando se encuentra en el hecho que todos los seres humanos son iguales y distintos a la vez.

Milagros Otero Parga [Valores constitucionales. Santiago de Compostela: Universidad Santiago de Compostela, 1999] consigna que "nada es igual o diferente en si mismo sino referido a algo".

Al actuar relacionalmente, la igualdad permite disfrutar de un derecho o asumir un deber, luego de la comparación que una persona efectúe con referencia a otra, en función al patrón de parangón.

En ese contexto, opera la denominada regla de justicia establecida por Aristóteles en su libro La Política: “Tratar a los iguales de modo igual y a los desiguales de modo desigual".

La igualdad se sustenta en su propia naturaleza (seres libres, racionales, espirituales y sociales).

Marcial Rubio Correa [Estudio de la Constitución Política de 1993. Lima: Fondo Editorial de la Pontificia Universidad Católica del Perú, 1999], refiere que los seres humanos tienen algo de común e idéntico con el resto de sus congéneres, que para el caso nos representa y caracteriza como seres humanos.

La disimilitud, en cambio, se sustenta en las calidades accidentales o secundarias de cada ser humano en particular (edad, sexo, inteligencia, capacidad física, etc.); así como en la naturaleza de las cosas (situación y condiciones de las relaciones coexistenciales) que los rodean.

El Tribunal Constitucional en el caso Cámara Peruana de la Construcción (Expediente $\mathrm{N}^{\circ}$ 00261-2003-AA/TC), ha señalado que "la naturaleza jurídica de la igualdad reposa en una condición o presupuesto indispensable para el ejercicio de los distintos y plurales derechos individuales. Es decir, que funciona en la medida en que se encuentra conectado con los restantes derechos [...]".

En ese sentido, la igualdad es un principio-derecho que intenta colocar a las personas situadas en idéntica condición en un plano de equivalencia. Ello implica una conformidad o identidad por coincidencia de naturaleza, circunstancias, calidad, cantidad o forma. Ello de modo tal que no se establezcan excepciones o privilegios que excluyan a una persona de los derechos que se conceden con otra, en paridad sincrónica o concurrencia de razones.

De allí que la relación de igualdad sea expresión de justicia, en tanto asegura la armonía y concurrencia en los derechos establecidos en el ordenamiento jurídico. 
Se reconoce a la igualdad como un principio normativo de vinculación genérica. Este deviene en el atributo que tiene toda persona para que se le aplique la ley o se le trate en las mismas condiciones que a los semejantes que se encuentran en idéntica o similar situación.

Consiste en la afirmación a priori y de apodíctica homologación entre todos los seres humanos, en razón de la identidad de naturaleza que el derecho estatal se limita a reconocer y garantizar.

En ese sentido, la igualdad no es expresiva de la realidad personal que indica que cada persona es evidentemente única e irrepetible, sino del mundo de las normas que reconoce que todas las personas tienen una misma naturaleza; y por tal son portadoras de dignidad.

Dicha igualdad conlleva a lo siguiente:

- La abstención de toda acción legislativa o jurisdiccional tendente a la diferenciación arbitraria, injustificable y no razonable.

- La existencia de un derecho subjetivo destinado a obtener un trato idéntico, en función de hechos, situaciones y relaciones homólogas entre dos o más personas.

María Isabel Garrido Gómez [La igualdad en el contenido y en la aplicación de la ley. Madrid: Dykinson, 2009] plantea que la igualdad consiste en reconocer que todos los seres humanos son sujetos de derechos; por ende, titulares de deberes y obligaciones. Ese reconocimiento en principio, no tiene que ser explicado pues se presume justo; en cambio, es exigible la justificación de una regla de diferenciación, so pena de ser cuestionada por arbitraria e injusta.

La igualdad busca regular de manera uniforme, las situaciones similares; ergo, consiste en la ausencia de discriminación, privilegio, favor o preferencia de unos seres humanos sobre otros.

A través de su verificación práctica procura una simetría de consecuencias jurídicas en pro de similares oportunidades o posibilidades de realización coexistencial para todos; lo que implica una tarea promotora para el acceso cabal e integro de los derechos fundamentales de la persona.

El principio de igualdad se concretiza en el plano formal mediante el deber estatal de abstenerse en la generación legal de diferencias arbitrarias o caprichosas; y en el plano material conlleva a la responsabilidad del cuerpo político de proveer las optimas condiciones para una simetría de oportunidades para todos los seres humanos.

La igualdad se encuentra resguardada cuando se acredita la existencia de los requisitos siguientes:

a) Paridad, uniformidad y exactitud de otorgamiento o reconocimiento de derechos u obligaciones ante hechos, supuestos o condiciones semejantes.

b) Paridad, uniformidad y exactitud de aplicación de la ley, para las personas sujetas a idénticas circunstancias y condiciones. 
Iván Díaz García [“Igualdad en la aplicación de la ley. Concepto, jusfundamentalidad y consecuencias”. En: Revista Ius et Praxis, $\mathrm{N}^{\circ}$ 2. Chile: Facultad de Derecho de la Universidad de Talca, 2012] consigna que en los casos de paridad existe coincidencia en la totalidad de las propiedades fácticas jurídicamente relevantes. Ello conlleva a aplicar la misma disposición jurídica interpretada con determinación de la misma consecuencia jurídica. En los casos de no paridad, al no haber coincidencia sobre la totalidad de las propiedades fácticas jurídicamente relevantes; ello conlleva a aplicar una disposición diferente o atenerse a consecuencias jurídicas disímiles.

La quiebra de la noción igualdad se produce cuando a través del proceso de formulación o interpretación-aplicación de la ley, esta genera consecuencias jurídicas disímiles entre una persona y otra, por el mero hecho de tales. En suma, aparece ante el establecimiento de derechos, facultades, atribuciones, deberes, responsabilidades o sanciones diferentes, a pesar de ser idénticas las conductas o situaciones de las personas involucradas en dicho proceso.

La conceptualización efectuada a la expresión igualdad, lleva a como derecho en dos planos convergentes: como principio y como derecho.

$\mathrm{Al}$ respecto, veamos lo siguiente

\section{2.- La igualdad como principio}

Este se constituye en la pauta rectora de la organización de la sociedad y de presupuesto ético-político para actuación programática del Estado. Por ende, deviene en la regla básica para estructurar una cierta forma de vinculación política; la misma que además el cuerpo político debe garantizar, preservar y dar contenido a través de la dación de políticas públicas, leyes, actos administrativos y resoluciones judiciales.

En puridad, cumple simultáneamente una función cimentadora en cuanto se constituye en una columna para la constitución y sostenimiento del Estado Democrático y Social de Derecho; y una función orientadora en cuanto sirve de marco de referencia para las tareas de legislación, administración de los servicios públicos e impartición de justicia.

Dicho principio debe ser asumido como un mandato de optimización que apunta a su verificación jurídica y social. El principio de igualdad exige del Estado simultánea y sincrónicamente, de un lado, una vinculación negativa o abstencionista y de otra, una vinculación positiva o intervencionista.

La vinculación negativa o abstencionista está referida a tratar igual a los iguales y diferente a los diferentes, quedando vedada la posibilidad que a través de la ley (expresión de una regla general y abstracta) se pueda auspiciar situaciones discriminatorias de cualquier índole.

La vinculación positiva o intervencionista está referida a tratar deferentemente a un sector de la población por un lapso determinado, mediante la denominada acción afirmativa o discriminación a la inversa. 
El Tribunal Constitucional en los casos Cámara Peruana de la Construcción y Máximo Yauri (Expedientes $\mathrm{N}^{\circ}$ 00261-2003-AA/TC y N 00018-2003-AI/TC) ha precisado los alcances de la igualdad como principio; a saber:

a) La igualdad como límite para la actuación estatal (ámbito legislativo, administrativo y jurisdiccional). Esta comprende aspectos vinculados con la elaboración, interpretación, aplicación y ejecución de las leyes en sentido lato.

b) La igualdad como mecanismo de reacción jurídica frente al hipotético caso de arbitrariedad en el ejercicio del poder.

c) La igualdad como valladar impeditivo para el establecimiento de situaciones basadas en criterios prohibidos (diferenciación atentatoria a la dignidad de la persona).

d) La igualdad como pauta basilar para el accionar del Estado, a efectos que remueva los obstáculos políticos o sociales, que restringen de hecho, la igualdad de oportunidades entre los seres humanos.

La noción de igualdad de oportunidades conlleva a conceptualizar y distinguir la igualdad formal de la igualdad sustancial.

La igualdad formal se presenta como una exigencia al legislador o al juzgador de no establecer diferencias injustificadas o irrazonables en la ley o en una resolución administrativa o judicial. Más aún, sus determinaciones normativas deben ser abstractas y generales.

La igualdad sustancial se presenta como una exigencia de adopción de políticas públicas destinadas a promover la equiparación respecto al acceso de la cobertura de necesidades básicas (agua, luz, alimentación, educación, transporte). Ello con el propósito de asegurar el libre desarrollo de la personalidad de todos los miembros de la comunidad; para lo cual debe generarse la igualdad de oportunidades.

\section{3.- La igualdad como derecho}

La noción de igualdad es percibida como una facultad o atribución exigible individual o colectivamente, por medio de la cual las personas deben ser tratadas simétrica y homólogamente ídem, tanto en el contenido de las leyes como en las aplicaciones de las mismas; siempre que no existan razones fundadas para un tratamiento distinto.

En tal sentido, el derecho a la igualdad se constituye, prima facie, en aquello que obliga tanto a los poderes públicos como los particulares a actuar uniformemente respecto a las personas que se encuentren en las mismas condiciones o situaciones; así como tratar de manera desigual a las personas que se encuentren en circunstancias disímiles. En este escenario dicho trato dispar debe apuntar a la consecución de un fin legítimo; el mismo que debe ser conseguido mediante la adopción de la medida más idónea, necesaria y proporcional.

En consecuencia se erige como un derecho fundamental de la persona oponible en todos los ámbitos de la vida coexistencial. 


\section{4.- La distinción entre igualdad como principio e igualdad como derecho}

Como principio implica un postulado o proposición con sentido y proyección normativa o deontológica que, como tal, constituye parte del núcleo del sistema constitucional de fundamento democrático.

Como derecho comparte el reconocimiento de la existencia de una facultad o atribución conformante del patrimonio jurídico de la persona y derivado de su naturaleza, que consiste en ser tratado igual que los demás en función de hechos, situaciones o acontecimientos coincidentes o distinto en razón de hechos, situaciones o condiciones distintas.

\section{5.- Los ámbitos de aplicación del principio-derecho de igualdad}

La idea de igualdad puede ser observada en relación al sistema jurídico o al sistema político social. El objetivo final de todo ello será la consagración de la libertad y la justicia.

Al respecto, veamos lo siguiente:

\section{a) La igualdad en relación al sistema jurídico}

La igualdad es observada como condicionadora vital de los procesos de elaboración, interpretación, aplicación y ejecución de la ley.

En ese contexto, sirve para consolidar la seguridad jurídica, ya que obliga al sistema a generar un marco de estabilidad y certeza.

Para tal efecto, se vislumbra a través de las nociones de igualdad ante la ley e igualdad en la aplicación de la ley. $\mathrm{Al}$ respecto, veamos lo siguiente:

\section{- La igualdad en la elaboración de la ley}

Se refiere a la exigencia de contenidos normativos generales y abstractos; vale decir, preceptivamente impersonales e indeterminados en relación con sus destinatarios, así como proposiciones en términos de supuestos que apuntan a un debe ser, en el que quedan encuadradas cualquier situación que pudiera darse en la realidad.

En ese contexto, opera como un límite a la discrecionalidad del legislador. Así, supone que este se encuentre impedido de configurar pautas preceptivas diferentes cuando no existen situaciones de hecho relevantes para ello. De allí que el legislador se encuentra vedado de establecer distinciones artificiosas o arbitrarias ante hechos, sucesos o acontecimientos que involucren a personas ubicadas en un plano de identidad absoluta, o que en caso de no existir dicha homología, estas careciesen de relevancia para fijar una regla de diferenciación. 
Walter Gutiérrez Camacho y Juan Manuel Sosa Sacio [“El derecho a la igualdad”. En: La Constitución comentada. Lima: Gaceta Jurídica, 2005] exponen que ella "impone un límite constitucional a la actuación del legislador, al no poder apartarse de este marco impuesto por el ordenamiento, para crear normas que sin más, contravengan la igualdad de trato.

[...] implica la posibilidad de que toda persona pueda defenderse frente a normas estatales que contengan diferencias irrazonables y que afecten su situación jurídica o sus legítimas expectativas”.

\section{- La igualdad en la aplicación de la ley}

Se refiere a la eficacia de las normas y la adecuación funcional de los operadores administrativos y jurisdiccionales con dicho principio-derecho constitucional. Por ende, opera como un límite a la actuación del aplicador de la ley; el cual no puede modificar arbitrariamente el sentido de sus decisiones en casos sustancialmente similares. En consecuencia, el respeto a la igualdad es la expresión de imparcialidad por parte del ente administrativo o jurisdiccional.

Ello supone la obligación de aplicar la ley de manera efectivamente semejante a todas las personas que se encuentren en la misma condición o circunstancia; o que en caso de inexistencia de homología, esta careciese de relevancia para fijar una regla de diferenciación.

El Tribunal Constitucional español en el caso Justo de las Cuervas Ganza (STC 46/1982) referido a una indefensión procesal en una diligencia previa, ha señalado que un mismo órgano jurisdiccional no puede modificar arbitrariamente el sentido de sus decisiones en casos sustancialmente iguales. En caso de existir la necesidad de modificar un sentido interpretativo, debe ofrecerse una fundamentación suficiente y razonable.

El Tribunal Constitucional en el caso Instituto Superior Tecnológico No Estatal Peruano de Sistemas SISE (Expediente $\mathrm{N}^{\circ}$ 01279-2002-AA/TC) ha señalado que la aplicación uniforme de la ley es una regla general que opera cuando existe una identidad sustancial entre los supuestos de hechos confrontados, lo cual no necesariamente deber ser plena; en tal sentido, basta con que se verifiquen suficientes elementos comunes que permitan considerar que los supuestos de hecho analizados son jurídicamente iguales, y merecer una aplicación isononómica de la norma.

Dicha expresión de igualdad en la aplicación de la ley supone lo siguiente:

- El órgano jurisdiccional debe ser el mismo en todas las circunstancias.

- Los supuestos de hecho descritos en los procesos o procedimientos deben ser sustancialmente idénticos.

- La existencia de una jurisprudencia o precedente vinculante sobre la materia.

- Existencia de un trato homólogo y simétrico.

Francisco J. Laporta [“Imperio de la ley y seguridad jurídica”. En: Estado, justicia y derechos. Barcelona: Ariel, 2002] señala que el desconocimiento de la aplicación homóloga de la ley plantea la idea proditora de parcialidad objetiva y subjetiva. 
La parcialidad objetiva aparece en las causas tasadas -en donde existe un marco preceptivo claro, regulado y preciso- lo que motiva al justiciable a poner en tela de juicio la idoneidad moral del juzgador.

La parcialidad subjetiva aparece en aquellas causas vinculadas a hechos, creencias o experiencias de vidas que "gobiernan" malhadadamente al juzgador; las mismas que lo incitan a aplicar de manera desemejante los alcances de una ley.

\section{b) La igualdad en relación al sistema político-social}

Se refiere a la inducción del fomento de políticas económico-sociales que formalizadas a través de la ley, coadyuven a plasmar la denominada igualdad sustancial. Esta se consagra cuando todas las personas pueden acceder sin mengua de su propio esfuerzo, a la cobertura de sus necesidades básicas.

En ese contexto, es que aparece la satisfacción mínima en cuanto al acceso de bienes y servicios indispensables para asegurar una calidad de vida "humana".

Ello supone un esfuerzo y una atención del Estado, a favor de aquellas personas que por sí mismas no pueden cubrir la totalidad de sus necesidades básicas; lo cual en los hechos afecta su dignidad, desvigoriza su capacidad de autonomía y mutila el desarrollo de su personalidad.

Esta falta razonable de cobertura personal de las necesidades básicas, supone condiciones para la existencia digna o la viabilidad del despliegue de las potencialidades físicas, psíquicas e intelectuales.

Dicha expresión expresa una identidad esencial en las condiciones de existencia.

En esa orientación, la igualdad de oportunidades organiza que la "partida" en la plasmación del proyecto de vida coexistencial con libre desarrollo de la personalidad, se efectúe dentro de condiciones económicas y sociales básicamente uniformes y simétricas.

La diferencia que dichas medidas establecen implican "aumentar" las oportunidades de aquellas personas con "menores" oportunidades por razones estructurales; vale decir, por condiciones ajenas a su propia voluntad personal.

Nuestra Constitución ha perfilado la construcción de un Estado Democrático Social; lo que impele a que el cuerpo político ponga especial énfasis en la promoción de los derechos fundamentales de segunda generación. Estos guardan una directa relación con la posibilidad de una vida digna y cabal realización coexistencial de las personas.

En ese sentido, las políticas sociales en pro de la igualdad de oportunidades y de acción normativa, comprenden por mandato constitucional previsto en los artículos 4, 7 y 23, entre otros, al niño, el adolescente, la madre y el anciano en situación de abandono; a la persona incapacitada física o mentalmente; así como a la madre, el menor o

el impedido que tienen la calidad de trabajador. Estas, en suma, pueden ser potenciales sujetos beneficiados, en los casos de normas y medidas de esa naturaleza. 


\section{6.- La igualdad y la diferenciación}

Es inobjetable que la idea básica de igualdad tiene su fundamento en la naturaleza humana; es decir, que todas las personas participan de la misma condición de personas (seres libres, racionales, espirituales y sociales). Empero, ello no implica desconocer la existencia de las denominadas "calidades accidentales" de cada individuo, así como tampoco el concepto de la naturaleza de las cosas en el ámbito de las interacciones personales.

Así, cada ser humano es igual a los otros en naturaleza, pero distinto en lo referido a las "calidades accidentales". Estas hacen referencia a las características físicas-psíquicas-intelectuales-sociales específicas y concretas, que sin alterar su esencia, se agrupan a ella para constituir su condición personal, única e intransferible. Por ende, es apodíctica la afirmación que los seres humanos son iguales y distintos a la vez.

Francisco Fernández Segado [ob. cit.] expone que "es evidente que el principio de igualdad no impone que todos los destinatarios de las normas hayan de tener inexcusablemente idénticos derechos y obligaciones. Por el contrario a situaciones distintas pueden acordarse situaciones jurídicas diferenciadoras".

Susana Mosquera Monelos [El derecho fundamental de igualdad. Lima: Palestra, 2006] expone que el principioderecho de igualdad proscribe la discriminación, mas no excluye la posibilidad de plantear una diferenciación. Por ende, no postula la absolutez de la paridad, cuando existe razonabilidad para plantear una diferencia de trato.

En efecto, es incuestionable que cada persona tiene su propia realidad físico-psíquica-intelectual. En ese aspecto, se pueden mencionar como elementos diferenciadores la inteligencia, el talento, el carácter, el temperamento, la personalidad, la sensibilidad axiológica, la estatura, el peso, el vigor físico, la edad, etc.

Asimismo, la igualdad no se encuentra reñida con normas diferenciadoras que se dicten en razón de la "naturaleza de las cosas"; las cuales hacen referencia a las específicas características de lo particular, singular o privativo de un hecho, situación o circunstancia. Es decir, comprende lo sui generis de su contenido y la necesidad por razones de justicia del apartamiento de las reglas genéricas.

En puridad, la diferenciación surge por la necesidad de establecer regulaciones jurídicas esencialmente distintas de aquellas que contemplen las relaciones o situaciones indiferenciadas, comunes o genéricas.

El tratamiento jurídico de las personas debe ser igual, salvo en lo atinente a la diferencia de sus "calidades accidentales" y de la naturaleza de las cosas que los vinculan coexistencialmente. El tratamiento desigual no será injustificado, en tanto no se afecte la dignidad de las personas.

La igualdad supone por definición dos o más hechos, situaciones y relaciones jurídicas que sean comparables entre sí para determinar la regulación coexistencial y la generación de un trato igual o diferenciado para las personas involucradas. En ese contexto, se introduce el análisis de las calidades accidentales de las personas y/o la naturaleza de las cosas; lo cual liga distintivamente las relaciones coexistenciales de las personas ubicadas en un mismo espacio, tiempo y sujeción estatal. 
En ese aspecto, las calidades accidentales y la naturaleza de las cosas hacen percibir que en toda relación jurídica debe existir un determinado orden, peculiaridades y características singulares que en consuno dan sentido y razón de ser a esta. Por ende, en aras de plasmar el mayor grado de justicia, es deseable que en todo vínculo imperativoatributivo queden claramente delimitados los rasgos esenciales que generan su existencia normativa; dado que estos son los que deben condicionar axiológicamente la materia objeto de regulación.

En puridad, dicho orden y rasgos específicos e intransferibles son los que hacen que una relación jurídica sea de un determinado tipo y no de otro.

El principio de igualdad no impide al operador del derecho, consagrar entre las personas distinciones que obedezcan a las calidades accidentales o diferencias que las circunstancias prácticas establecen de manera indubitable. Así, la existencia de una regla de diferenciación, debe ser apreciada en relación con la finalidad y los efectos de la medida legal adoptada sobre la materia.

La diferenciación sustentada en las calidades accidentales o la naturaleza de las cosas, no afecta en modo alguno la dignidad de los sujetos vinculados con una norma de esta connotación.

La regla de diferenciación debe acreditar las condiciones siguientes:

a) Debe apuntar a la realización de un fin constitucionalmente válido y legítimo.

b) Debe efectuar una distinción razonable y adecuada al fin perseguido.

c) Debe establecer una concordancia lógica y materialmente alícuota entre el fin perseguido y el medio empleado por la norma. Por ello, enervar las restricciones o limitaciones innecesarias o excesivas de algún o algunos derechos fundamentales.

El establecimiento de una diferenciación jurídica debe de perseguir un resultado jurídico legítimo a la luz de la moral y los valores del derecho; así como el acreditamiento de una razonable relación de proporcionalidad entre los medios empleados y la finalidad que la motiva.

La justificación de la diferenciación tiene como valladar el denominado tope abstracto-histórico; esto es, tiene los límites de la moral y la ideología imperante en un espacio-tiempo y las circunstancias contextuales a las que se encuentran sujetos los destinatarios de la norma.

La diferenciación debe aspirar a una intencionalidad legítima, determinada, concreta y específica; es decir, deberá asentarse en una justificación objetiva y razonable, de acuerdo con certeros juicios de valor generalmente aceptados. En suma, la distinción no debe obedecer a apreciaciones sujetas a interpretación.

En ese sentido, no cabe hablar válidamente de un proceso diferenciador de trato, cuando este se basa en supuestos de hecho o situaciones subjetivas.

Dicha diferenciación implica una relación efectiva entre el trato desigual que se establece, el supuesto de hecho y la finalidad que se persigue alcanzar. 
La razonabilidad de la medida se afirma en consideraciones lógicas y propósito lícito dentro del tiempo-histórico que "vive" la sociedad.

Javier Pérez Royo [La diferenciación de los derechos fundamentales. Curso de Derecho constitucional. Madrid: Marcial Pons, 2007] señala que la igualdad que predica la Constitución no apoya unas consecuencias jurídicas ininterrumpidamente ecuménicas y absolutas, ya que a guisa de ejemplo, recuerda que los hombres son iguales por naturaleza, pero diferentes por su condición de ciudadanos adscritos a estados diferentes. Ergo, es distinguible y diferenciable en ciertas materias la semejanza normativa entre nacionales y extranjeros.

En suma, la idea de igualdad admite la identidad y homología de trato; como la diferenciación y distinción del mismo, siempre que en uno u otro caso, la medida se erija sobre la base de una justificación apropiada.

Francisco J. Laporta [“El principio de igualdad: Introducción a su análisis”. En: Sistema, Revista de Ciencias Sociales, $\mathrm{N}^{\circ}$ 67. Madrid, 1985], señala que el tratamiento diferenciado se justifica en atención a los criterios siguientes:

a) Criterio de satisfacción de necesidades. Aplicase a favor de aquellos sujetos que tienen la urgencia de que se les asegure la protección de un derecho, la prestación de un servicio o el goce de un bien; los cuales no generan para otros el mismo grado de apremio en su satisfacción.

b) Criterio de retribución de merecimientos. Aplicase a favor de aquellos sujetos que se han hecho merecedores de premios, recompensas o beneficios por la realización de algo socialmente valorable.

c) Criterio de reconocimiento de aptitudes. Aplicase a favor de aquellos sujetos portadores de atributos necesarios o útiles para el desempeño de una labor (inteligencia, conocimientos, capacidad física, personalidad, etc.).

d) Criterio de consideración del status. Aplicase a aquellos sujetos que por razón de la función deben merecer un trato diferente (protocolo, prerrogativas funcionales, uso de insignias, prendas, etc.).

Francisco J. Laporta [ob. cit.] señala que un texto normativo es coherente con los alcances y sentido del principio de igualdad, cuando su funcionamiento queda abierto a todas las personas en virtud de no acreditar ningún atisbo de discriminación; y que luego de satisfacer dicha prioridad, adjudica beneficios o castigos diferenciadamente, a partir de rasgos distintivos relevantes. En ese mismo contexto es igualmente aceptable para el derecho, el que la pauta basilar relativa a la igualdad quede subordinada al desarrollo pleno de otros principios constitucionales valorados como de superior jerarquía en específicas y concretas circunstancias.

Esto último puede ejemplificarse a la luz de lo establecido en el caso Pedro Moreno Alonso (STC 114/1987) en donde el Tribunal Constitucional español amparó el reclamo de un miembro de la Fuerza Armada; al cual se le había denegado el acceso a la pensión, por haber sido condenado por la comisión de tráfico ilícito de drogas.

Al respecto, dicho colegiado señaló lo siguiente: "La ley puede condicionar el nacimiento del derecho a una pensión de retiro o de jubilación a la observancia de determinados requisitos objetivos, tales como haberse prestado servicio de voluntariado militar durante un corto tiempo, o el haber realizado actividades laborales durante un 
lapso determinado como trabajador o funcionario para generar tal derecho. Empero, no se puede vincular dicha consecuencia prestacional a la observancia de ciertas condiciones como la buena conducta, por no guardar una relación razonable de causalidad con la finalidad perseguida. Es decir, no hay una razonable relación entre el medio y el fin".

En suma, debe advertirse que la defensa del derecho a la igualdad no impide la existencia de normas diferenciadas; en tanto estas acrediten una justificación objetiva y razonable.

María Isabel Garrido Gómez [ob. cit.] plantea de alguna manera las máximas siguientes:

a) Cuando no existe una razón suficiente es exigible un trato igualitario.

b) Cuando existe una razón suficiente es permisible un trato diferenciado.

c) Cuando el trato diferente recae sobre supuestos de hechos desiguales en su propia naturaleza, es exigible que este aspire a la consolidación de la igualdad sustancial en pro de la satisfacción de un fin constitucional.

\section{7.- La igualdad y la discriminación}

La igualdad en relación al sistema jurídico (igualdad ante la ley e igualdad en aplicación de la ley) expone la proscripción frontal de toda forma de discriminación.

La discriminación deviene en un trato desigual y arbitrario a personas sujetas a condiciones o situaciones idénticas, bien sea para el otorgamiento de ventajas o en la imposición de cargas. Ello conlleva una agravada e injustificable distinción que afecte la dignidad de la persona; lo cual incluso puede llegar al extremo de la negación de la propia condición humana.

El Comité de Derechos Humanos de Naciones Unidas en su Observación General Nº 18 (1987) consigna que la discriminación en términos de comparación entre personas, se apoya de un lado, en un acto de distinción, exclusión, restricción o preferencia subjetiva e irrazonable; y del otro, en la anulación o menoscabo en el reconocimiento de goce de un derecho.

En esa línea, la Corte Europea de Derechos Humanos en el caso Lakovos Thlimmenos vs. Grecia (2000) ha señalado que "el derecho o no ser discriminado en el goce de los derechos [...] también es violado cuando los Estados sin una justificación objetiva y razonable, no tratan diferente a personas cuya situación es significativamente diferente". En dicha litis el accionante señalaba que el impedimen to de acceder a un cargo público por haber sufrido condena por el incumplimiento de vestir un uniforme militar, no contemplaba el caso de un testigo de Jehová que formuló una objeción de conciencia.

La discriminación conlleva a consecuencias jurídicas de distinción, excepción o separación tendientes a anular o menoscabar la dignidad humana; por ende, en impedir el pleno reconocimiento o ejercicio de los derechos fundamentales o la igualdad de trato en relación al acceso indistinto de oportunidades. 
Joaquín García Morillo [“La cláusula general de igualdad”. En: Derecho Constitucional. Valencia: Tirant lo Blanch, 2002] señala que la discriminación solo puede producirse entre iguales; esto es, entre sujetos adscritos a hechos, sucesos, acontecimiento o condiciones semejantes.

En ese sentido, todo ordenamiento jurídico plantea reglas generales y abstractas que apuntan a que las personas sean tratadas de manera uniforme e idéntica, salvo que acrediten razones relevantes para que se establezcan reglas diferentes. De allí que Eduardo Rabossi ["Derechos humanos: el principio de igualdad y la discriminación”. En: Derecho a la igualdad. Buenos Aires: Lexis Nexis, 2007] estima que "la discriminación supone adoptar una decisión o llevar a cabo una acción prejuiciosa, parcial, injusta; así como consignar una distinción que, en definitiva, es contraria a algo o alguien [...] a partir de un tratamiento desigual que no resulta admisible".

La discriminación se presenta bajo las formas siguientes:

a) Directa. Esta aparece cuando el trato desigual se manifiesta de manera indiscutible e incontestablemente precisa.

b) Indirecta. Esta aparece cuando el trato desigual se manifiesta de manera colateral o encubierta lo que implica la necesidad de acreditar la discriminación a través de elementos adicionales. Expone una medida aparentemente neutra y carente de intención ilegítima; empero, al momento de su aplicación genera para un grupo un trato injustificadamente adverso. Tal el caso de la utilización de un motivo jurídicamente válido que sin embargo provoca una afectación de los derechos fundamentales de un grupo social en relación al resto. Es decir, que en su aplicación se debilita la razonabilidad de la medida. A guisa de ejemplo, ello se presenta en los procesos de evaluación con acreditación de conocimientos generales (matemática, lengua, historia) al personal de servicio de una repartición estatal.

La discriminación directa es realizada con expresa decisión de anular, proscribir, excluir; la discriminación indirecta es realizada con el mismo propósito, pero de manera encubierta.

La discriminación se asienta en el prejuicio social de dividir a los congéneres en iguales e inferiores; en respetables e irrespetables; en calificables y descartables.

Mediante esta práctica viciosa se suele excluir o menospreciar en razón a:

a) Características inmanentes. Estas son aquellas que aparecen por mero acto de nacimiento. Tal el caso de la raza, el sexo, etc.

b) Características incorporadas del medio social. Estas son aquellas que aparecen en función a nuestro entorno inmediato. Tal el caso del origen, la condición económica, el idioma, etc.

c) Características adoptadas. Estas son aquellas que aparecen por la libre decisión de la persona. Tal es caso del credo, filiación política, opción sexual, etc.

En función a lo expuesto, la proscripción de la discriminación presenta los elementos siguientes:

a) Reconocimiento que las personas más allá de sus diferencias accidentales comparten una misma naturaleza; y que, por ende, son intrínsecamente iguales. 
b) Exigencia que no se establezcan excepciones o privilegios que excluyan a unos de los que se concede a otros, en circunstancias y condiciones idénticas.

c) Reconocimiento del establecimiento de reglas de diferenciación siempre que aquellas no resulten irrazonables y desproporcionadas; vale decir, que no sean obra de la arbitrariedad

d) Determinación que las reglas de diferenciación específicas están sujetas al principio de inversión de la carga probatoria; esto es, corresponde al legislador o aplicador de la ley ofrecer las argumentaciones que prueben la razonabilidad y proporcionalidad de la medida adoptada.

Ahora bien, aun cuando la discriminación por regla general conlleva un tratamiento injustificadamente diferente, cabe residualmente la posibilidad de que esta aparezca en la circunstancia de disponerse la aplicación idéntica de una regla, sin considerar la producción de consecuencias jurídicas perjudiciales para aquellas que se encuentren en una situación de vulnerabilidad (tal como el caso de tasas e impuestos uniformes, etc.).

Desde una perspectiva histórica correspondió a la jurisprudencia norteamericana el dejar constancia de la lucha conceptualmente jurídica contra la discriminación.

Es del caso, que en 1880 se estableció en el Estado de California una norma por la cual los establecimientos que ofrecían servicios de lavandería deberían operar en locales construidos con material de piedra o ladrillo; ello a efectos de prevenir los incendios en dichos establecimientos. Empero, la norma dejaba abierta la posibilidad que los propietarios de los establecimientos con construcciones de madera pudieran acceder a una autorización especial para que fueran hechas con otro tipo de material menos costoso para la época.

En la ciudad de San Francisco funcionaban trescientas veinte lavanderías; de las cuales el setenta y cinco por ciento de ellas pertenecían a propietarios de origen chino (doscientas cuarenta lavanderías).

A la luz de esta posibilidad se presentaron muchas solicitudes, sin que en ningún caso se aprobase favorablemente alguna de las presentadas por aquellos.

Así, en el emblemático caso Yick Wo vs. Hopkins, la Corte Suprema norteamericana declaró que era inconstitucional la conducta asumida por los funcionarios estaduales de San Francisco, al aplicar una ley con criterio discriminador entre unos propietarios y otros por el solo hecho del origen.

Según nuestra Constitución, ninguna persona debe ser discriminada por alguna de las razones siguientes:

\section{a) Origen}

Hace referencia a la defensa contra la discriminación derivada del lugar de nacimiento o del trono de filiación.

b) Raza

Hace referencia a la defensa contra la discriminación derivada de la pertenencia a un grupo humano con ascendencia común o conformación física (color de piel, facciones y estructura anatómica predominante).

c) Sexo

Hace referencia a la defensa contra la discriminación derivada de razones orgánicas que distinguen al hombre de la mujer. 


\section{d) Idioma}

Hace referencia a la defensa contra la discriminación derivada de la utilización de una lengua, es decir contra un modo particular de comunicación fonéticas o escritural.

e) Religión

Hace referencia a la defensa contra la discriminación derivada de una creencia o dogma que vincula a los hombres con alguna divinidad o ser supremo.

\section{f) Opinión}

Hace referencia a la defensa contra la discriminación derivada de pareceres, dictámenes, juicios, etc., que postula una persona.

\section{g) Condición económica}

Hace referencia a la defensa contra la discriminación derivada de cierto tipo de estado o situación de poder adquisitivo, posesión de bienes o rentas, etc.

\section{h) Índole diversa}

Hace referencia a la defensa contra la discriminación derivada de factores múltiples; edad, discapacidad física, apariencia física, estatura, etc.

Es importante consignar que a raíz de vituperables actos de discriminación en algunas discotecas y pubs limeños, se dictó la Ley $\mathrm{N}^{\circ} 27049$, en donde se precisó que todos los consumidores tienen el derecho a la protección de sus intereses económicos, mediante el trato equitativo y justo en toda transacción comercial. Por ende, no pueden ser objeto de discriminación por motivo de raza, sexo, nivel socioeconómico, idioma, discapacidad, preferencias políticas, creencias religiosas o de cualquier índole, en la adquisición de productos y prestación de servicios que se ofrecen en locales abiertos al público.

Asimismo, se estableció que los proveedores no pueden establecer discriminación alguna respecto a los solicitantes de los productos y servicios que los primeros ofrecen en locales abiertos al público. Se consigna la prohibición de realizar selección de la clientela, excluir a personas o realizar prácticas similares, sin que medien causas tales como seguridad del establecimiento, tranquilidad de los clientes, u otras razones objetivas y justificadas.

Igualmente es dable consignar que mediante la Ley $N^{\circ} 27279$, estableció la figura delictiva de la discriminación.

\section{1.- La discriminación y el criterio de término de comparación}

La persona que denuncie la existencia de un régimen jurídico de trato desigual injustificable, tiene la obligación de exponer un término de comparación que sirva de base para determinar la vulneración del principio de igualdad. Para tal efecto, debe acreditar que otra persona situada en idéntica condición y circunstancia que la suya, se encuentra en una mejor condición o ha sido beneficiada con el goce de un régimen jurídico más favorable. 
Robert Alexy [“El sistema jurídico, principios jurídicos y razón práctica”. En: Madrid: Doxa, № 5, 1988], ha formulado las reglas siguientes:

a) Cuando no hay una razón suficiente para la justificación de un tratamiento desigual, entonces debe ser ordenado un tratamiento igual.

b) Cuando hay una razón suficiente para producir un tratamiento desigual, entonces debe ser ordenado un tratamiento desigual.

La razón suficiente implica el examen de las normas, con el objeto de observar las motivaciones y razones que se alegan para justificar si dicha diferenciación se encuentra conforme con los valores y principios constitucionales.

Dicha diferencia en el contenido de la ley o en el trato, es aceptable jurídicamente en tanto se acredite lo siguiente:

a) Existencia de una causa objetiva y razonable para fundamentar un contenido normativo distinto o un trato diferente, a un grupo de personas en relación a otras. La diferenciación no puede tener como objetivo la consagración del capricho, el despotismo, el nepotismo o la consecución de ventajas y beneficios como merced o gracia emanada del poder.

b) Existencia de una relación de proporcionalidad entre los medios empleados y el fin a alcanzarse a través del trato deferente. El concepto de proporcionalidad sirve como punto de apoyo para otorgar la ponderación valorativa entre principios constitucionales en conflicto.

La utilización de un valor o principio constitucional distinto al referido al de la igualdad no es suficiente para asignarle legitimidad a un proceso diferenciador. Ello únicamente es viable cuando se logra demostrar la existencia de una razón suficiente para otorgarle jerarquía prevalente en función a la naturaleza de las cosas.

Para tal efecto, debe realizarse una contrastación entre las pautas basilares en pugna.

A través de la demostración de la existencia de una razón suficiente, la aplicación deferente de un principio constitucional sobre el referido al de la igualdad, conlleva necesariamente la reducción del campo de aplicación de este último.

La labor de los entes jurisdiccionales consiste en determinar cuándo dicha reducción es proporcional, armoniosa, equilibrada y simétrica a la luz de una interpretación sistémica del texto fundamental.

Para tal efecto deberá tenerse en cuenta la necesaria adecuación entre los medios escogidos para la consecución jurídica del fin trazado; así como la necesidad de la utilización de los medios escogidos para el logro del fin trazado. En ese sentido, debe desvirtuarse la posibilidad que exista otra manera o forma de alcanzar el fin trazado.

La ineludibilidad de la utilización del medio escogido acarrea la oblación del principio de igualdad; el mismo que en dicho contexto resulta de menor jerarquía que aquel que se pretende resguardar vía la diferenciación jurídica. En el caso de nuestra Constitución son citables los casos del a asignación de prerrogativas diferenciadas a favor de 
los congresistas, vía la inviolabilidad parlamentaria, el antejuicio político, etc. Asimismo, la concesión del derecho de gracia; o la limitación de la propiedad en zona de frontera para los extranjeros.

El trato diferencial no debe sacrificar valores y principios que tengan una mayor relevancia que aquel o aquellos que se intentan satisfacer mediante dicha consecuencia jurídica desemejante.

Queda claro entonces que la diferenciación jurídica no debe "ofrendar" vilmente aquellos principios que en el "espacio" creado por la naturaleza de las cosas, tengan mayor relevancia que los restantes, incluido el relativo al de la igualdad.

\section{8.- La ponderación: El test de la igualdad}

A efectos de evaluar si una medida limitativa de derechos, principios, bienes o intereses constitucionales resulta conforme con el principio-derecho de igualdad, el Tribunal Constitucional en el caso Fiscal de la Nación (Expediente $\mathrm{N}^{\circ}$ 00004-2006-PI/TC) ha formalizado jurisprudencialmente la utilización del test de la igualdad.

La aplicación de dicho test es consecuencia de la aprobación de una norma "intervencionista" cuya consecuencia jurídica radica en restringir o limitar el ejercicio de un derecho fundamental, etc., en aras de permitir el goce de otro de la misma naturaleza. Tal el caso de una norma que prohíbe fumar en espacios públicos, la proscripción del trabajo nocturno a menores de edad, la imposición de una tasa o contribución, etc.

Dicha "intervención" es compatible con la Constitución a condición que se admita el respeto al principio de concordancia práctica.

La norma "intervencionista" opera sobre dos o más derechos fundamentales, de manera simultánea; a saber:

a) La consecuencia jurídica de la norma "intervencionista" apunta a resguardar, defender o asegurar el goce de un derecho fundamental (principio, bienes, etc.). Para tal efecto, el legislador se ve impelido a través de dicha norma a acotar o limitar el ejercicio de otro derecho de la misma jerarquía.

Dicha consecuencia es el objetivo y finalidad del acto legislativo intervencionista.

El objetivo alude al estado de cosas o situación jurídica que el legislador a través de la norma "intervencionista" pretende consumar.

La finalidad es el goce o plasmación del derecho fundamental, principio, bien o interés constitucional cuya realización debe lograrse mediante dicha acción “intervencionista.

En efecto, tras la expedición de la norma "intervencionista" se pretende la configuración de un nuevo, específico y completo "estado de cosas"; el cual debe ser compatible y armónico con la Constitución. 
b) La norma "intervencionista" provoca la restricción o limitación sobre otro u otros derechos fundamentales, principios, bienes o intereses constitucionales en aras del goce de algo que precedentemente se confiere injustificadamente.

Dicho texto es un proceso relevante para garantizar el principio de concordancia práctica en el goce de los derechos fundamentales. Este tiene carácter secuencial y preclusivo.

Lo expuesto indica que en caso la norma objeto de examen no logre cumplir los requisitos exigidos en un paso metodológico, el test debe concluir inmediatamente; debiéndose en consecuencia, declarar la invalidez de la prescripción legislativa.

El cumplimiento satisfactorio de cada uno de los pasos metodológicos indicará inexorablemente que la norma sigue formando parte del ordenamiento jurídico y debe ser aplicada para resolver una materia administrativa o judicial.

El test de igualdad consta de los pasos metodológicos siguiente:

\section{Primer paso:}

\section{Verificación de la diferencia legislativa entre las normas en pugna}

En este estadio se analiza jurisdiccionalmente si el supuesto de hecho observado (premisa o hipótesis de cuya realización depende la aplicación de una norma) observado como de supuesta diferenciación arbitraria (discriminación) es semejante en ambos casos.

La realización de este análisis plantea dos respuestas:

a) Que se acredite que ambos supuestos de hecho son iguales. En tal circunstancia queda plenamente evidenciada la existencia de una diferenciación arbitraria (discriminatoria). Por ende, la norma cuestionada deviene inmediatamente en inconstitucional.

b) Que se acredite que entre ambos supuestos de hecho tienen ciertas características que los hacen disímiles. En tal circunstancia queda plenamente evidenciada la existencia de una regla de diferenciación que debe ser objeto de un mayor análisis. Por ende, debe proseguirse con la utilización del test.

\section{Segundo paso:}

\section{Determinación del nivel de intensidad de la intervención en la igualdad}

En este estadio se analiza el grado o magnitud de la restricción o limitación de un derecho-principio o bien fundamental. 
En efecto, la intensidad de la medida legislativa "intervencionista" puede ser:

\section{a) Grado de intensidad grave}

Ello se produce cuando la diferenciación se sustenta en alguno de los motivos proscritos por la propia Constitución (raza, sexo, idioma, religión, opinión, etc.); lo que genera ya sea el impedimento discriminativo del ejercicio de un derecho de dicho rango o la aplicación de un principio o el resguardo de un bien o interés ídem.

\section{b) Grado de intensidad media}

Ello se produce cuando la diferenciación se sustenta en alguno de los motivos proscritos por la propia Constitución (raza, sexo, idioma, religión, opinión, etc.); lo que genera el impedimento o goce de un derecho, la aplicación de un principio o el resguardo de un bien o interés previsto en la ley u otra norma de menor jerarquía.

\section{c) Grado de intensidad leve}

Ello se produce cuando la diferenciación se sustenta en motivos distintos a los proscritos en la Constitución; empero, previstos en la ley u otra norma de menor jerarquía.

Cabe anotar que dichas calificaciones pueden provenir alternativamente de los aportes de la ciencia, la ética o las consideraciones comúnmente aceptadas por la sociedad dentro del espacio-tiempo correspondiente.

\section{Tercer paso:}

\section{Verificación de la existencia de un fin constitucional en la diferenciación}

En este estadio la existencia o no existencia de un fin constitucional que pudiere avalar la diferenciación puede ser observado en un plano general y en un plano específico.

En el plano general apunta a acreditar el respeto a las funciones de consolidación de la unidad política del Estado; la correcta aplicación de la competencia y cometidos políticos del Estado; el derrotero, rumbo y sentido histórico del Estado; y fundamentalmente del resguardo a la dignidad de las personas adscritas al Estado.

En el plano específico apunta a acreditar el beneficio de personas que se pretende otorgar; es decir, la consecución del acceso a un derecho fundamental hasta ese momento no planteado en su real magnitud; la aplicación de un principio rector; la defensa de un bien constitucional; o un interés constitucionalmente protegido.

Como consecuencia de este análisis aparece alguna de estas dos respuestas:

- Que la diferenciación no apunte a la cristalización de un fin constitucional. Por ende, la norma debe ser inaplicada y/o expulsada del ordenamiento jurídico. 
- Que la diferenciación apunte a la cristalización de un fin constitucional. Por ende, debe proseguirse con el test.

Cabe señalar, que en caso de duda acerca de la finalidad de la norma, opera el principio de presunción de constitucionalidad; lo que también conlleva a proseguir con el test.

\section{Cuarto paso:}

\section{Examen de idoneidad o adecuación}

En este estadio se verifica la utilidad de la medida legislativa para alcanzar la finalidad propuesta. Es decir, se trata de verificar la capacidad de asegurar el goce del derecho fundamental, la aplicación del principio o el resguardo del bien constitucional materia de la definición.

Dicha exigencia supone distinguir con claridad la relación existencial entre el objetivo y el fin de la norma diferenciadora.

Javier Barnes [“El principio de proporcionalidad. Estudio preliminar” En: Cuadernos de Derecho Público, N 5. Madrid: INAP, 1998] expresa que el objetivo supone determinar el "estado de cosas" particular y concreto que se busca conseguir; así como, precisar prolijamente el derecho fundamental, principio, bien o interés constitucional que sería consolidado o resguardo de una manera más efectiva a la situación jurídica preexistente.

En puridad, busca develar el vínculo existente entre el medio empleado (la medida legislativa diferenciadora o interviniente) y el fin propuesto. Ergo, se trata de conectar la correspondencia del medio empleado con el fin propuesto.

Dicho vínculo se establece en dos fases:

- La relación armónica y coherente entre la medida legislativa diferenciadora (medio de intervención) y el objetivo (estado de cosas o situación jurídica que se pretende configurar).

- La relación armónica y coherente entre el objetivo (estado de cosas o situación jurídica que se pretende configurar y la finalidad propuesta (ejercicio del derecho fundamental, aplicación del principio o resguardo del bien o interés constitucional).

$\mathrm{Al}$ respecto, a guisa de ejemplo veamos lo siguiente:

En una Universidad Particular se establece en el Reglamento de Estudios como requisito para acceder al otorgamiento de una beca, el que el estudiante acredite insolvencia económica y pertenencia al quinto superior de rendimiento académico (medida diferenciadora). 
Ello a efectos de que se otorgue dicho beneficio solo a aquellos estudiantes que lo requieran por razones económicas y lo ameriten por razones académicas (objetivos de la medida diferenciadora).

Los requisitos planteados en la medida legislativa apuntan a resguardar el uso adecuado de los fondos asignados para el otorgamiento de dicho beneficio; así como salvaguardar la excelencia académica que redundara en la imagen y reputación de la Universidad (fin de la medida diferenciadora).

\section{Quinto paso:}

\section{Examen de necesidad o idoneidad}

En este estadio se verifica acreditar la idoneidad de la medida legislativa diferenciadora; es decir, implica comprobar el carácter indispensable de este, en razón de no existir otra opción más calificada para alcanzar el objetivo propuesto (“estado de cosas" deseado).

Dicha exigencia obliga a efectuar un análisis comparativo entre la medida establecida en la norma diferenciadora frente a otras alternativas desestimadas o inexploradas por el legislador.

David Giménes Gluck [Juicio de igualdad y Tribunal Constitucional. Madrid: Borda, 2004] señala que "la limitación ha de ser necesaria para alcanzar el fin en la medida en que cualquier otra opción supondría una carga mayor sobre el derecho afectado".

En ese escenario hipotético se hace indispensable demostrar que ninguna otra medida resulta menos limitativa o restrictiva que la escogida por el legislador.

En ese contexto, se debe declarar la invalidez de la norma diferenciadora cuando existe una opción legislativa distinta y menos grave para el derecho fundamental objeto de "intervención". Para los criterios de eficacia, temporalidad y probabilidad.

El criterio de eficacia indica la capacidad de generar el efecto deseado o propuesto a través de la medida legislativa dictada.

El criterio de temporalidad indica la capacidad de generar la consecución del objetivo-fin de la norma diferenciada se obtendrá en un lapso más breve.

El criterio de probabilidad indica la capacidad de una mayor seguridad de plasmar la constitución del objetivo-fin de la norma diferenciadora.

\section{Sexto paso:}

\section{Examen de proporcionalidad strictu sensu}


En este estadio se efectúa un tertium comparationis (término de comparación) entre la medida legislativa adoptada (medio) y la finalidad perseguida, en donde debe existir una relación de equilibrio razonable.

Se trata de verificar si la intensidad o magnitud del trato diferenciado, es el que lógicamente corresponde para la optimización del goce de un derecho que en este caso particular y concreto resulta ecuánime y previsible.

De lo expuesto se colige que el texto desigual no debe "sacrificar" derechos que tengan mayor peso que aquel que se quiere satisfacer mediante el aludido trato.

En puridad, se trata de realizar un balance entre los prejuicios que genera la norma diferenciadora y los beneficios que este fomenta. Así, se debe constatar que la medida legislativa en cuestión es calificable de proporcionada.

En efecto, la medida legislativa es proporcionada cuando la utilidad de la norma compensa cualitativamente los menoscabos que causa.

La compensación debe ser establecida en términos cualitativos, ya que lo importante es determinar el linaje, clase, importancia, atributos, elementos o calidades que resulta de la aplicación de la norma diferenciadora, antes que en la mera suma de perjuicios.

En suma, la norma diferenciadora es proporcionada cuando justifica las cuestiones siguientes:

- El porqué de la medida.

- El cómo se aplica en la medida.

- El valor e importancia de su utilidad.

A manera de resumen, cabe señalar que el test es un instrumento metodológico que fija los límites de configuración legal de un derecho fundamental, aplicación de un principio, bien o interés constitucionalmente protegido. En ese sentido, la intervención del legislador apoya la justificación del objetivo y facultad de una norma diferenciadora.

En ese marco, el test permite determinar lo siguiente:

a) La utilidad o no utilidad de la medida legislativa, visto el objetivo y finalidad a alcanzarse.

b) La necesidad de su existencia, en virtud de no existir otra opción más óptima.

c) La moderación de la limitación o restricción de un derecho y la consecución de espacios de acceso al goce de otro u otros de la misma jerarquía jurídica.

\section{9.- La acción positiva, afirmativa o de discriminación inversa}

La desigualdad de trato de hecho y de derecho no justificables a la luz de la Constitución, muchas veces encuentra su sustento en hábitos sociales, o en la indolencia, desidia y falta de celo estatal. En ese contexto, esta realidad opera colectivamente sobre grupos sociales cuantitativamente minoritarios en relación a otros; o por falta de suficiente 
poder de influencia desde una perspectiva política, económica, social o cultural.

Dicha situación viene siendo combatida a través de la figura jurídica de la discriminación promotora de la igualdad o acción positiva o afirmativa.

Esta implica la aplicación de una medida especial de favorecimiento de carácter temporal, destinada paliar o remediar la situación de discriminación estructural (condiciones económicas y sociales), de un grupo de la comunidad; la cual se sustenta en una distinción objetiva, razonable y con la finalidad de asegurar condiciones mínimas de dignidad y procura del libre desarrollo de la personalidad, vía la igualdad de oportunidades.

Al respecto, existe una "conciencia social" en la comunidad política, acerca de las condiciones de trato en que se encuentran "enclaustrados" determinados grupos sociales, los cuales comparten una misma razón para ser objeto de postración y una misma incapacidad para enervarla per se.

A mayor abundamiento, el derecho fija su atención en aquellos grupos que son objeto de prácticas discriminativas sobre la base de perjuicios arraigados; los cuales les impiden desplegar plenamente su personalidad en distintos aspectos de la vida coexistencial.

R. Turner [Citado por Elisa Sicoma Hernaiz. Acción positiva y empleo de la mujer. Madrid, 1999] recuerda que dicha figura conocida en el sistema jurídico norteamericano fue instituida en el marco de "una historia por la lucha de los derechos civiles que tuvo como punto de partida el trato discriminatorio y dispar que tradicionalmente han recibido, entre otros, la comunidad negra y las mujeres".

En puridad, dicha expresión fue acuñada por el presidente John F, Kennedy en la Orden Ejecutiva 10925 (1961), mediante la cual se promovía el acceso a la función pública de los negros e indígenas oriundos.

Por ende, aun cuando pareciese contradictorio, en el derecho constitucional se ha ido construyendo pacientemente una suerte de discriminación a la inversa, a efectos de compensar diversas formas de relegamiento a la que han estado sometidos determinados grupos sociales. Para ello, se impele al Estado a la adopción de una acción legisferante positiva o afirmativa, tendiente a corregir dichas discapacidades en el goce de los derechos fundamentales y la igual real de oportunidades de las personas.

Nuria González Martin ["El principio de igualdad, la prohibición de discriminación y las acciones positivas". En: Derechos fundamentales y Estado. Memoria del VII Congreso de Derecho Constitucional. México: Universidad Nacional Autónoma de México, 2002] define la acción positiva o afirmativa como aquellos "tratamientos preferenciales".

David Giménes Gluck [Una manifestación polémica del principio de igualdad: acciones positivas moderadas y medidas de discriminación a la inversa. Valencia: Tirant lo Blanch, 1999] consigna que "el trato formalmente desigual que basa la diferencia de trato en la pertenencia a un grupo que comparte la posición de un rango minusválido 
[...] que se caracteriza principalmente por sus medidas que forman un colectivo por su pertenencia al mismo, no por circunstancias individuales".

José Ignacio Casas [Guía didáctica. Madrid: Ministerio de Asuntos Sociales, s.f.] señala que consiste en el "establecimiento de medidas temporales que, con el fin de establecer la igualdad de oportunidades en la práctica, permiten $[\ldots]$ corregir aquellas situaciones que son el resultado de $[\ldots]$ sistemas sociales discriminatorios".

Cabe señalar que la doctrina de la acción positiva o afirmativa encuentra particular importancia en la búsqueda del goce efectivo de los denominados derechos de segunda generación (educación, trabajo, seguridad social, vivienda, etc.). De allí que genere tratamiento preferencial en el acceso a la educación superior, la contratación laboral, otorgamiento de becas de perfeccionamiento, etc. En América Latina, aparecen también medidas en el campo de los derechos políticos (v.g. las cuotas electorales).

La responsabilidad del Estado en pro de la igualdad sustancial demanda también la renovación de los obstáculos de orden cultural, político, económico, etc., los cuales en la praxis restringen la vigencia plena de dicho derecho. Así, en la búsqueda de la afirmación simétrica de oportunidades, el cuerpo político resulta comprometido con la adopción de medidas legislativas, en principio temporales, en favor de grupos desplazados.

Mediante la acción positiva o afirmativa un grupo social históricamente excluido es objeto de tutela antidiscriminatoria, vía una legislación especial, deferente y por lo general transitoria.

La acción positiva o afirmativa cuenta con los elementos siguientes:

\section{a) Causa notoria}

Los motivos que han generado el relegamiento de grupo, no puede ser removido o suspendido unilateralmente por el grupo afectado.

\section{b) Temporalidad}

La legislación especial y deferente tiene vigencia, en principio, por un lapso determinado o determinable. En el primer caso se materializa con una fecha concreta de auto abrogación; en el segundo caso se verifica cuando se alcanza el resultado de nivel de igualdad.

Ahora bien, un caso de excepción absoluta se genera en el trato deferente en materia laboral para los discapacitados (ciegos, inválidos, etc.).

\section{c) Discriminación a la inversa}

La legislación especial y deferente conlleva la adopción de medidas de preferencia, a efectos que el grupo históricamente desplazado pueda en un tiempo determinado o determinable alcanzar el mismo trato en el goce de los derechos fundamentales. 


\section{d) Especificidad}

La legislación especial y deferente hace referencia a medidas determinadas, singulares y delimitadas.

Dicha acción positiva o afirmativa por parte del Estado, genera como consecuencia lo siguiente:

a) La identificación del obstáculo social, económico cultural, etc.

b) La identificación del grupo discriminado, el cual a través de esta forma de tutela es dotado de mayores atribuciones, beneficios, facultades, etc., que el resto de la población.

c) La acción positiva o afirmativa tiene simultáneamente efectos resarcitorios, pero también reequilibradores y redistribuidores de oportunidades.

d) La acción positiva o afirmativa como bien expone Nuria González Martin [ob. cit.] consigue “quebrar viejos patrones de segregación y jerarquía; lo que en la praxis conlleva de un lado, a la remoción de obstáculos; y, del otro, a la de promover condiciones para que los derechos fundamentales devengan en reales y efectivos.

Desde una perspectiva aparecerá en la India, a raíz de la decisión del Imperio Británico de emprender una discreta modificación en dicha sociedad, al establecer a finales del Siglo XIX una reserva de plazas educativas en favor de los miembros de las clases más deprimidas; las mismas que tradicionalmente solo eran ocupadas por sujetos pertenecientes a la casta brahmánica.

Debe recodarse que las castas son estratificaciones sociales consagradas hace más de 2500 años, tras la invasión indo-arya; la cual implementó una política de segregación mediante la instauración de rígidas leyes sustentadas en la religión hinduista. Así, se estructurará la casta brahmánica (sacerdotes y maestros); la casta chatria (políticos), la casta vaishía (comerciantes y artesanos); la casta shuda (obreros y campesinos); amén de colocar en el último escalafón a los dalits o parias, que tienen asignadas las labores más pueriles.

Tras la independencia, en 1950 durante el gobierno de Sri Pandit Jawa Harlal Nehru (g. 1947-1964) se dictaron acciones afirmativas denominadas reservaciones o cupo de plazas administrativas y de educación superior, en favor de personas pertenecientes a las castas más bajas; en función de la acreditación de requisitos tales como: indicadores de ingreso, nivel formativo, ocupación laboral del cabeza de familia.

En el mundo europeo se le implementará a partir de 1976, en aras de combatir la postración laboral de las mujeres en el ámbito laboral.

La acción afirmativa se reforzará en los Estados Unidos por la vía jurisprudencial, a raíz del caso Regentes de la Universidad de Davis vs. Bakke (1978).

Al respecto, es dable señalar que en la Universidad Estatal de Davis (California) se estableció un proceso de admisión bajo dos supuestos distintos. En el primer caso, el proceso de selección era abierto para todos los interesados; exigiéndoseles un puntaje mínimo para el ingreso. En el segundo caso, dicho proceso estableció un cupo especial del dieciséis por ciento de vacantes a favor de postulantes negros, asiáticos y latinos, los cuales se encontraban exonerados de obtener el puntaje mínimo. 
El joven blanco Allan Bakke no pudo obtener el puntaje mínimo para el acceso abierto para la Facultad de Medicina; empero, varios postulantes negros con puntajes inferiores al demandante, obtuvieron vacantes gracias al cupo benigno.

La Corte Suprema de los Estados Unidos consideró que la universidad estaba constitucionalmente facultada para crear programas especiales de ingreso con cupo benigno, a favor de sectores sociales relegados.

Dicho fallo avaló la figura de la discriminación inversa y promotora de la igualdad, fundándose en las razones siguientes:

a) Implicaba una acción afirmativa tendiente a corregir prácticas discriminatorias asentadas sobre hábitos sociales afectantes para ciertos grupos sociales desplazados históricamente.

b) Implicaba una acción afirmativa para la construcción de una sociedad más justa e integrada por la vía de la movilización social y la transformación del orden cultural.

En 1987, la Corte Suprema se pronunció en el caso Paul Johnson vs. La Agencia de Transportes de la Ciudad de Santa Clara (California).

La referida empresa adoptó una política promotora del contratación y ascenso laboral en favor de las mujeres o trabajadores pertenecientes a las minorías étnicas o con algún tipo de discapacidad.

El accionante señalaba no haber obtenido un ascenso, por haberlo discriminado en favor de la señorita Diana Joice. El ente jurisdiccional declaró constitucional dicha práctica, ya que con ello se ayudaba a resolver el desequilibrio en aras laborales tradicionalmente segregacionistas.

La discriminación a la inversa conlleva a que un grupo acreditadamente excluido, pueda gozar de una protección especial, a efectos de conseguir paulatinamente su cabal homologación con el resto de la población.

Desde la perspectiva del derecho comparado, para cierto sector de la doctrina española el artículo 9.2 de su Constitución, permite la introducción de las llamadas cuotas o cupos benignos, en aras de promover una igualdad real de oportunidades o posibilidades. Dicho precepto textualmente señala que: "Corresponde a los poderes públicos promover condiciones para que la libertad y la igualad del individuo y los grupos en que se integran, sean reales y efectivas".

En la reforma constitucional argentina de 1994 aparece la misma figura en el artículo 37, respecto al acceso a los cargos electivos y partidarios a favor de las mujeres; igualmente en el inciso 23 del artículo 75 respecto al trato a los niños, mujeres, ancianos y discapacitados.

En nuestro país, el Tribunal Constitucional en el caso Jorge Power Manchego-Muñoz (Expediente $\mathrm{N}^{\circ}$ 00018-2003$\mathrm{AI} / \mathrm{TC}$ ) ha señalado que no se considera discriminatoria aquella acción legislativa que establezca tratos diferenciados con el objeto de promover la igualdad real de oportunidades a condición que esté sujeta a la regla de temporalidad. 
En el ámbito del ordenamiento jurídico nacional son citables los casos siguientes:

La Ley N 25003 de fecha 23 de febrero de 1990, dictada durante el gobierno del doctor Alan García Pérez, cuyo nomem juris era la "Ley de la Bolsa de Trabajo", que obligaba a las empresas constructoras a contratar cuando fuere el caso a un veinticinco por ciento de operarios sindicalizados.

Dicha disposición tenía por objeto proteger a los trabajadores sindicalizados de los actos de discriminación ocupacional, por su sola razón de tales.

A pesar que dicha ley con cupo benigno fue declarada constitucional por el ex Tribunal de Garantías Constitucionales, durante el gobierno del ingeniero Alberto Fujimori en su fase dictatorial, fue abrogada mediante el Decreto Ley $\mathrm{N}^{\circ}$ 25588 de fecha 1 de junio de 1992.

El artículo 116 de la Ley № 26859 cuyo nomem juris es Ley Orgánica de Elecciones contempla un cupo benigno de treinta por ciento de mujeres en la conformación de las listas de candidatos al Congreso de la República. Dicha regulación tiene por objeto promover mayores oportunidades de participación representativa de las mujeres.

La Ley $\mathrm{N}^{\circ} 27277$ establece que las universidades públicas deben reservar en los procesos de admisión y en los cursos de especialización técnica, un número de vacantes adecuadas para los funcionarios, servidores públicos e hijos de estas víctimas del terrorismo.

La Ley $\mathrm{N}^{\circ} 28869$ establece un cupo benigno de no menos un veinte por ciento a favor de ciudadanos menores de 29 de años de edad, en las listas de regidores municipales.

La Ley N² 29973 establece la obligatoriedad de las entidades públicas a emplear personas con discapacidad en una proporción no menor al 5\% del total de sus trabajadores; y en el caso de entidades privadas la proporción es del 3\%.

En esa perspectiva, el Tribunal Constitucional en el caso Colegio de Notarios de Lima, Callao y Arequipa (Expedientes Acumulados $\mathrm{N}^{\circ}$ 00001-2003-AI/TC y No 00003-2003-AI/TC) ha señalado que "cuando el artículo 103 de la Constitución prevé la imposibilidad de dictar leyes especiales 'en razón de la diferencia de las personas' abunda en la necesaria igualdad formal prevista en el inciso 2 de su artículo 2, según lo cual el legislador no puede ser generador de diferencias sociales; pero en modo alguno, puede ser interpretado de forma que se limite el derecho y el deber del Estado, mediante 'acciones positivas' o de 'discriminación inversa', ser promotor de la igualdad sustancial entre los individuos".

Dicha posición se asume en atención a las responsabilidades estatales de promover la igualdad de oportunidades de cara a la defensa de la dignidad de la persona humana. 
Alexy, R. (1988). El sistema jurídico, principios jurídicos y razón práctica. Madrid: Doxa, N. 5. Azuela M. (1995). Derecho, sociedad y libertad. México: Universidad Iberoamericana. Barnes, J. (1988). El principio de proporcionalidad. Estudio preliminar. Cuadernos de Derecho Público, N. ${ }^{\circ}$ 5 .

Madrid: INAP.

Carón de Beaumarchais, P. (1779) Las Bodas de Figaro.

Casas, J. Guía didáctica. Madrid: Ministerio de Asuntos Sociales, s.f.]

Comité de Derechos Humanos de Naciones Unidas (1987). Observación General Nº 18.

Constitución Política del Perú (1993)

Corte Europea de Derechos Humanos (2000) Lakovos Thlimmenos vs. Grecia.

Declaración de los Derechos del Hombre y del Ciudadano (1789)

Díaz, I. (2012). Igualdad en la aplicación de la ley. Concepto, jusfundamentalidad y consecuencias. Revista Ius et

Praxis, N. ${ }^{\circ}$ 2. Chile: Facultad de Derecho de la Universidad de Talca.

Eduardo Rabossi [“Derechos humanos: el principio de igualdad y la discriminación”. En: Derecho a la igualdad. Buenos Aires: Lexis Nexis, 2007]

Fernández, F. (1992). El sistema constitucional español. Madrid: Dykinson.

García Belaúnde, D. (1989). Teoría y práctica de la Constitución peruana. Lima: Eddili.

García, J. (2002). La cláusula general de igualdad. Derecho Constitucional. Valencia: Tirant lo Blanch. Garrido, M. (2009). La igualdad en el contenido y en la aplicación de la ley. Madrid: Dykinson.

Giménes Gluck D. (1999). Una manifestación polémica del principio de igualdad: acciones positivas moderadas y medidas de discriminación a la inversa. Valencia: Tirant lo Blanch.

Giménes Gluck, D. (2004). Juicio de igualdad y Tribunal Constitucional. Madrid: Borda.

González, N. (2002). El principio de igualdad, la prohibición de discriminación y las acciones positivas.

Derechos

fundamentales y Estado. Memoria del VII Congreso de Derecho Constitucional. México: Universidad

Nacional

Autónoma de México.

Gutiérrez, W., Sosa, J. (2005). "El derecho a la igualdad”. La Constitución comentada. Lima: Gaceta Jurídica.

Hernaiz, E. (1999). Acción positiva y empleo de la mujer. Madrid.

Laporta, F. (1985). El principio de igualdad: Introducción a su análisis. Sistema, Revista de Ciencias Sociales, $\mathrm{N}^{\mathrm{o}}$

67. Madrid.

Laporta, F. (2002). Imperio de la ley y seguridad jurídica. Estado, justicia y derechos. Barcelona. Mendonca, D. (2012). Apuntes constitucionales. Una guía para el ciudadano. Asunción: Intercontinental Editora, Centro de Estudios Constitucionales. 
Mosquera, S. (2006). El derecho fundamental de igualdad. Lima: Palestra.

Otero, M. (1999). Valores constitucionales. Santiago de Compostela: Universidad Santiago de Compostela.

Pérez, J. (2007). La diferenciación de los derechos fundamentales. Curso de Derecho constitucional. Madrid: Marcial Pons.

Rubio, F. (1993). El principio de legalidad. En: Revista Española de Derecho Constitucional, Año 13, N. ${ }^{o}$ 30. Madrid: CEC.

Rubio Correa, M. (1993). Estudio de la Constitución Política de 1993. Lima: Fondo Editorial de la Pontificia Universidad Católica del Perú.

Tribunal Constitucional (2003), Expediente N. ${ }^{\circ} 00261-2003-\mathrm{AA} / \mathrm{TC}$.

Tribunal Constitucional (2003). Expediente N. $.^{\circ} 00018-2003-\mathrm{AI} / \mathrm{TC}$.

Tribunal Constitucional (2002). Expediente N. ${ }^{\circ} 01279-2002-\mathrm{AA} / \mathrm{TC}$.

Tribunal Constitucional español. (1982) STC 46/1982.

Tribunal Constitucional español (1987). STC 114/1987.

Tribunal Constitucional (2006). Expediente N. ${ }^{\circ} 00004-2006-\mathrm{PI} / \mathrm{TC}$.

Tribunal Constitucional. (2003). Expedientes Acumulados $\mathrm{N}^{\circ} 00001-2003-\mathrm{AI} / \mathrm{TC}$ y N ${ }^{\circ}$ 00003-2003-AI/TC. 